\title{
EDICIÓN ESCOLAR EN ESPAÑA, IDENTIDAD, CULTURA POLÍTICA Y CONTEXTO: LA ENCICLOPEDIA DALMAU CARLES-PLA
}

\author{
School publishing in Spain, identity, political culture and \\ context: Dalmau Carles-Pla Encyclopedia
}

\section{Emilio Castillejo Cambra*}

Fecha de recepción: 05/09/2016 • Fecha de aceptación: 05/12/2016

Resumen. Este artículo hace un análisis comparativo de los contenidos ideológicos (identidad, cultura política, ciudadanía) de las ediciones de la Enciclopedia Cíclico-Pedagógica (Grado Medio) de la editorial Dalmau CarlesPla de 1927 (Dictadura primorriverista, aunque su redacción corresponde todavía a la Restauración), 1936 (Segunda República) y 1953 (franquismo). Los rasgos ideológicos sustanciales de la edición de 1927 son el corporativismo, el elitismo, un liberalismo respetuoso con la constitución histórica (monarquía, catolicismo) y un patriotismo español compatible con el foralismo y el catalanismo. Monarquía, catolicismo, corporativismo, elitismo, patriotismo... son valores compartidos por el régimen franquista: la edición de 1953 puede conservar la redacción anterior, aunque introduce retoques para legitimar el régimen franquista, eliminar de raíz el catalanismo o exaltar la Hispanidad. La edición de 1936 legitima el marco legal republicano, pero al conservar el corporativismo, el elitismo, el monarquismo, el catolicismo... de redacciones anteriores, no legitima valores republicanos como la libertad de conciencia, el laicismo, el reformismo social.... Ello nos habla de las dificultades para alterar el sistema de valores que impuso la oligarquía que estableció en España el régimen liberal.

Palabras clave: Enciclopedia Dalmau Carles; Cultura política; Identidad; Restauración Alfonsina; Dictadura primorriverista; Segunda República; Franquismo.

Abstract. This article makes a comparative analysis of the ideological contents (identity, political culture, citizenship) of the editions of the Cyclic-Pedago-

\footnotetext{
" Departamento de Geografía e Historia. Centro Asociado de la UNED - Pamplona. C. Señorío de Amocain, 47. 31016 Pamplona. España. ecastillejo@pamplona.uned.es.
}

Cómo citar este artículo: Castillejo Cambra, Emilio. «Edición escolar en España, identidad, cultura política y contexto: la Enciclopedia Dalmau Carles-Pla», Historia y Memoria de la Educación, 6 (2017): 487-521. 
gical Encyclopedia (intermediate level) of the Dalmau Carles-Pla publishing house in 1927 (Primo de Rivera's dictatorship, although the draft still corresponds to the prior Restoration), 1936 (Second Republic) and 1953 (Franco's regime). The outstanding ideological features of the 1927 edition are corporativism, elitism, a liberalism respectful of the historical constitution (Monarchy, Catholicism) and a Spanish patriotism compatible with the foralism and catalanism. Monarchism, Catholicism, corporativism, elitism, patriotism.... These are all values shared by Franco's regime: the 1953 edition retains many of the previous texts although it introduces several modifications that serve to legitimize the Franco regime, root out the Catalonian nationalism and exalt Spanishheritage. The 1936 edition legitimizes the Republican legal framework, but as it preserves the corporativism, elitism, monarchism and Catholicism... from previous drafts, it does not legitimize Republican values such as freedom of conscience, secularism, social reformism.... This tells us something about the difficulties involved in altering the value system imposed by the oligarchy which established the liberal regime in Spain.

Keywords: Encyclopedia Dalmau Carles; Political culture; Identity; King Alfonso's; Restoration; Primo de Rivera dictatorship; Spanish Second Republic; Francoism.

Josep Dalmau Carles (1857-1928), ${ }^{1}$ maestro normal de inquietudes republicanas, fundó la editorial Dalmau Carles en 1904, cuyos manuales escolares se difundieron en España e Hispanoamérica: Método completo de lectura, España mi patria.... Con su yerno Joaquim Pla Cargol (1882-1978), funda en 1919 la editorial Dalmau Carles-Pla, entre cuyas publicaciones figura la famosa Enciclopedia cíclico-pedagógica. ${ }^{2}$ Sus libros en catalán guardan relación con el nacionalismo cultural (Reinaxença, Associació Protectora de l'Ensenyança Catalana) y político: éxito electoral de Solidaritat Catalana en 1906, Mancomunitat de Catalunya constituida en $1914 .^{3}$ Nuestro autor puede inscribirse dentro de un movimiento de renovación pedagógica del magisterio gerundense de principios del siglo Xx: apren-

\footnotetext{
1 Nombraré a este autor en catalán y sin tilde; en las citas bibliográficas a pie de página, respeto la referencia en castellano (y la tilde), tal y como aparece en las enciclopedias utilizadas.

2 Eduardo Connolly de Pernas, «Josep Dalmau Carles: maestro, republicano y editor», Hibris: revista de bibliofilia, 34 (2006): 37-40.

3 Josep González- Agàpito y Salomó Marqués i Sureda, «El libro escolar en catalán», en Historia ilustrada del libro escolar en España. II. Del Antiguo Régimen a la Segunda República, dir. Agustín Escolano Benito (Madrid: Fundación Germán Sánchez Ruipérez, 1997), 561- 571.
} 
dizaje activo, escuelas de verano, revistas pedagógicas. ${ }^{4}$ Y nuestra editorial, como otras catalanas (Bastinos, Paluzie), en la órbita de la Escola Nova. ${ }^{5}$ Pocos libros escolares, entre los que se encuentran los de Dalmau Carles-Pla, han contado con ilustradores de la talla de Joaquim Renart. ${ }^{6}$ Pero también es cierto que toda esa renovación pedagógica y editorial no es ajena a la que se está produciendo en el resto de España. ${ }^{7}$

Este artículo pretende un análisis comparativo de ciertos contenidos ideológicos entre las ediciones de 1927, 1936 y 1953 de la Enciclopedia cíclico-pedagógica, Grado Medio de la editorial Dalmau Carles-Pla. Si es cierto que los autores de manuales escolares no sólo reflejan conocimientos disciplinares, sino también su ideología e incluso «la que estos atribuyen de forma anticipada e implícita a los sujetos que lo han de leer y estudiar», ${ }^{8}$ cabe esperar una adecuación ideológica de las ediciones citadas a los contextos históricos que les corresponden: Dictadura de Primo de Rivera, Segunda República y franquismo. Este artículo pretende demostrar que esa adecuación es cierta, pero también que el contexto histórico concreto (regímenes políticos) no es suficiente. Primero, porque el tiempo educativo suele ser más lento que el tiempo político (en 1927, pasados ya cinco años del golpe militar de Primo de Rivera, Dalmau Carles no ha revisado los contenidos de la Enciclopedia y sigue legitimando la Restauración), y segundo, porque es necesario inscribir la edición escolar

\footnotetext{
${ }^{4}$ Salomó Marqués, «L'esplendor del magisteri gironí», en La renovació de l'escola pública del Empordà a tot Catalunya (1900-1939), ed. Salomó Marquès et alii (Figueres- Girona: Generalitat de Catalunya, Societat d'Història de l'Educació dels Paisos de LLengua Catalana, 2013), 11- 18.

5 Josep González Agàpito et alii, Tradició i renovació pedagògica, 1898- 1939 (Barcelona: Institut d'Estudis Catalans, Publicacions de l'Abadìa de Montserrat, 2002): 260-265. También Maria Pilar Navarro, «Escola Nova: una nova pedagogia de la lectura a Catalunya», Educació i Historia: Revista d'Història de l'Educació, 22 (2013): 65-92.

${ }^{6}$ Montserrat Castillo, Grans il.lustradors del llibre per a infans catalans, 1905- 1939 (Barcelona: Biblioteca de Catalunya, 1997), 94- 96, 99-102.

${ }^{7}$ Sobre esa renovación: Agustín Escolano Benito, «Tradición e innovaciones en los libros de iniciación a la lectura de la España de entre siglos» en Historia ilustrada del libro escolar en España. Del Antiguo Régimen a la Segunda República, dir. Agustín Escolano Benito (Madrid: Fundación Germán Sánchez Ruipérez, 1997), 229-254, y «Libros escolares para programas cíclicos. Epítomes, compendios y tratados. Las primeras enciclopedias», en Historia ilustrada del libro escolar en España. Del Antiguo Régimen a la Segunda República, 425- 448; Federico Gómez R. de Castro, «Lecciones de cosas y centros de interés» en Historia ilustrada del libro escolar en España. Del Antiguo Régimen a la Segunda República, 449- 466.

${ }^{8}$ Gabriela Ossenbach y Miguel Somoza, Los manuales escolares como fuente para la historia de la educación en América Latina (Madrid: UNED, 2009), 41.
} 
en contextos más amplios, en modelos educativos que los trascienden. Las tres ediciones de la citada Enciclopedia encajan dentro del modo de educación tradicional-elitista, que arranca con el Estado liberal y pervive en España hasta la Ley General de Educación de 1970, en el que la asignatura de Historia «contribuye a afianzar el doble componente clasista y nacionalista bajo el que nace el poder de la burguesía». ${ }^{9}$

\section{REFERENTES IDENTITARIOS: ESPAÑA, EUROPA E HISPANIDAD}

Desde la perspectiva de la Gramática Textual, la identidad es una representación mental compartida por un grupo, que se adquiere desde la infancia pero que cambia conforme se construye, casi siempre va asociada a una imagen positiva del nosotros y negativa del otro, incluye ideologías subyacentes, y sirve para la reproducción de grupos: su discurso general es modificado por el uso (semántica del discurso) y por el contexto (pragmática del discurso). ${ }^{10}$ Yo no hablo de contexto lingüístico, sino de contexto histórico: se trata aquí de averiguar en qué medida el discurso identitario sobre España o la Hispanidad es modificado por el contexto.

\section{Identidad nacional: patriotismo incluyente y excluyente}

La nación española es el referente identitario más reforzado por los manuales escolares. El nacionalismo de Estado, en nuestro caso el español, es una forma de legitimar, en torno a una comunidad mística, a grupos sociales establecidos en un centro de poder. Para ello recrea la historia de la nación, simulando su antigüedad y olvidando la violencia primitiva fundadora. ${ }^{11}$ Las páginas de Educación Social de la Enciclopedia Dalmau Carles de 1927 legitiman el patriotismo español desde un punto de vista afectivo, casi religioso: la Patria es «nuestra segunda madre», y «es deber nuestro sacrificar por ella nuestra tranquilidad, nuestros bienes e incluso nuestra vida», como hicieron los «héroes» del pasado. Las metáforas

\footnotetext{
${ }^{9}$ Raimundo Cuesta Fernández, Sociogénesis de una disciplina escolar: la Historia (Barcelona: Pomares Corredor, 1997), 94.

${ }^{10}$ Encarna Atienza Cerezo y Teun A. Van Dijk, «Identidad social e ideología en libros de texto españoles de Ciencias Sociales», Revista de Educación, 353 (2010): 57- 106.

${ }^{11}$ Alfonso Pérez- Agote, «Nación y nacionalismo: la politización de la identidad colectiva», en Sociedad y política. Temas de sociología política, eds. Jorge Benedicto y María Luz Morán (Madrid: Alianza, 1995), 121.
} 
familiares o la significatividad de la muerte y del sacrificio emparentan una vez más el nacionalismo con la religión. La edición de 1936 acentúa esa afectividad: la Patria es «la gran familia que nos cobija, nos atiende y nos preserva», debemos defenderla "con nuestra sangre». La edición franquista no necesita cambios. ${ }^{12}$

Las páginas de historia corroboran ese patriotismo. Las tres ediciones coinciden en el mismo relato fundador. La referencia a «los españoles» de las cavernas guarda relación con mitos de antigüedad; la supuesta mezcla de iberos y celtas, "raza enérgica, vigorosa y amante de su independencia», que dio lugar a los celtíberos, tiene relación con mitos de carácter. Los contactos de los «españoles» con otros pueblos refuerzan mitos de resistencia: los españoles «aprendieron muchas industrias» de los fenicios, si bien la «avaricia» de éstos provocó «un alzamiento general de los celtíberos» (españoles); tras la "guerra de independencia» contra Roma, el latín se convierte en «lengua nacional». Con los visigodos, la nación ya tiene religión y Estado: «Los visigodos legaron a España [...] el Catolicismo, la Nacionalidad y la Monarquía». ${ }^{13}$

La «Reconquista» se convierte en un mito de recuperación: «Borrados, ante el común peligro, los odios de raza entre godos y españoles, se funden en un solo pueblo cristiano y juran vencer o morir por la Religión y la Patria». Patriotismo y religión son el nexo que une a los españoles: una narración perfectamente asumible por el franquismo, aunque no recoja los mitos del nacionalcatolicismo eclesial sobre la "pérdida de España» por los pecados y escándalos (sexuales) de sus reyes y sobre la «Reconquista» como purga por esos pecados. ${ }^{14}$ Para Dalmau Carles, como para el liberalismo doctrinario, el catolicismo es un elemento constitutivo de la nación española pero, al contrario que para el nacionalca-

12 José Dalmáu Carles, Enciclopedia cíclico-pedagógica, Grado Medio (Gerona: Dalmáu Carles, Pla, 1927), 638-639, Enciclopedia cíclico-pedagógica, Grado Medio (Gerona- Madrid: Dalmau Carles, Pla, 1936), 609-610, y Enciclopedia cíclico-pedagógica, Grado Medio (Gerona-Madrid: Dalmáu Carles, Pla, 1953), 600-601. Sobre la relación nacionalismo-religión: Jose Santiago, «Las formas de sacralización del nacionalismo: un desafío a la secularización», en Sagrado/ Profano. Nuevos desafíos al proyecto de la modernidad, eds. Josetxo Beriain e Ignacio Sánchez de la Yncera (Madrid: CIS, 2010), 349- 365.

13 José Dalmáu Carles, Enciclopedia (1927), 375-389, Enciclopedia (1936), 337-341, y Enciclopedia (1953), 319-332.

${ }_{14}$ José Dalmáu Carles, Enciclopedia (1927), 388 y 395-396, Enciclopedia (1936), 340 y 347-348, y Enciclopedia (1953), 331 y 337. 
tolicismo ortodoxo, España no es el brazo armado de Dios: tiene vida propia. La edición de 1953, por tanto, no necesita cambios: al fin y al cabo, los manuales de Formación del Espíritu Nacional del Partido Único, al contrario que los vinculados a un nacionalcatolicismo eclesial (la mayoría de los de Educación Primaria), tampoco subordinan la Historia de España al providencialismo.

La narración de Dalmau Carles de "la santa obra de la Reconquista», frente al modelo unitarista de Juan de Mariana, sigue el modelo de Esteban de Garibay (1533-1599), que yuxtapone la historia de los distintos reinos peninsulares ${ }^{15}$, una perspectiva coherente con el catalanismo del autor. Por eso, la prosopopeya convierte los distintos entes territoriales en sujeto: «Vasconia, que nunca había sido sometida, da el grito de independencia»; "Cataluña conquistó su independencia» con Wifredo el Velloso y "crea un estado floreciente»; Aragón tras la muerte de Sancho III «comenzó a existir como nación independiente». Pero no olvida una perspectiva unitaria: el cristianismo (frente a la «morisma») y sentimientos compartidos (los «indomables vascos» "pelean con ardor asturiano») actúan como aglutinante entre los reinos del norte; se establecen paralelismos entre ellos ( Casi al mismo tiempo que Pelayo iniciaba la Reconquista en Covadonga, el valeroso Otger la emprendía en Cataluña»); se lamenta la división del patrimonio territorial por cuanto implícitamente ralentiza el camino hacia la unidad (Alfonso VII "cometió el error político de repartir sus estados entre sus hijos», Jaime I cometió la misma "grave falta»); entiende como «definitiva» la unión de Castilla y de León en 1230 o la incorporación "para siempre» de Navarra a Castilla en 1515, y usa términos anacrónicos como «España durante la Reconquista». Para reafirmar esa perspectiva unitaria, la edición de 1953 añade unos mapas en que los reinos cristianos quedan separados entre sí por delgadas líneas discontinuas, mientras la línea que separa éstos de Al-Andalus es continua y gruesa. ${ }^{16}$

La edición franquista de 1953 introduce más novedades en el relato a partir de los Reyes Católicos. Para las ediciones de 1927 y 1936, «Aragón

\footnotetext{
${ }^{15}$ Sobre esos modelos: Baltasar Cuart Moner, «La larga marcha hacia las historias de España en el siglo XVI», en La construcción de las Historias de España, coord. Ricardo García Cárcel (Madrid: Marcial Pons, 2004), 111-123.

16 José Dalmáu Carles, Enciclopedia (1927), 397-408, Enciclopedia (1936), 348- 360, y Enciclopedia... (1953), 331-351.
} 
y Cataluña se unieron a Castilla», prosopopeya que convierte a ambas en sujetos con voluntad. La edición de 1953 añade nuevos significados de raigambre falangista: con los Reyes Católicos se obtiene «por vez primera, la Unidad Española y la plasmación del Destino Imperial de la Patria». De otra parte, en las ediciones de 1927 y 1936 el patriotismo español no excluye un foralismo romántico. Refieren la abolición por Felipe II de las «libertades aragonesas»; explican la rebelión de Cataluña (sujeto histórico) en 1640 "porque no se respetaban sus legítimos privilegios»; afirman que en 1714 Cataluña fue «castigada con la pérdida de sus fueros y privilegios y sometida a un régimen de terror»; no olvidan que en 1876, como "castigo" por el apoyo de las Vascongadas al carlismo, se suprimieron «casi todos sus fueros». El franquismo, en cambio, es incompatible con identidades complejas: el sentimiento de una España unida desde los Reyes Católicos excluye otros sentimientos de pertenencia. Cambia la ideología subyacente. Por eso, la edición de 1953 obvia los retoques de Felipe II en los fueros de Aragón y justifica su intervención en ese reino como «castigo» por «la conducta de los aragoneses»; no legitima la rebelión de 1640, sólo señala que Cataluña «vivió en abierta rebelión»; aligera las consecuencias de la intervención de Felipe V en Cataluña («después de un terrible asedio y repetidos asaltos, [las tropas de Felipe V] penetraron» en Barcelona); suprime la referencia a la abolición de los fueros vascos. ${ }^{17}$ Sin duda, en el paso de una identidad compleja a otra simple influyen razones crematísticas y la censura. Pero esos giros no son ajenos al catalanismo político burgués y conservador: también Francesc Cambó, cada vez que vio el peligro de una revolución, sacrificó su reformismo y su catalanismo. ${ }^{18}$

La nación se comporta como un organismo vivo que nace, aprende, crece, madura y decae. Pero las distintas ideologías subyacentes localizan la decadencia nacional en momentos distintos. Las ediciones de 1927 y 1936, condicionadas por el liberalismo (valoración negativa del absolutismo), el foralismo (aborrecimiento del centralismo) y la idea de

\footnotetext{
17 José Dalmáu Carles, Enciclopedia (1927), 418-420, 424 y 442, Enciclopedia (1936), 370-372, 376 y 394, y Enciclopedia (1953), 363, 364, 367 y 385.

18 En 1917, tras protagonizar la Asamblea de Parlamentarios, pasa al gobierno de Antonio Maura; en 1936, espantado por la deriva revolucionaria de la República, se inclina por Franco: Lluis M. de Puig, "Francesc Cambó: paradoxes i contradiccions. Una història en revisió», Annals de l'Institut D'Estudis Gironins, vol. 39 (1998), 378-394.
} 
progreso (la expulsión de judíos y moriscos disminuyó la población, la agricultura y el comercio), localizan el inicio de «la decadencia de nuestra patria» en el reinado de Felipe II, pues a pesar de sus «victorias brillantísimas» en Europa y de conservar en España «la paz de las conciencias» (legitimación indirecta de la unidad católica), "gastó mucha sangre y riquezas en guerras desastrosas». Con los Austrias del siglo XVII «continúa» esa decadencia. Los Borbones del siglo XVIII significan la recuperación: con Felipe V, «España volvió a figurar entre las naciones europeas de primer orden», Carlos III fomentó la enseñanza, la agricultura, la industria, las ciencias. La edición de 1953, condicionada por el nacionalcatolicismo, integrismo y militarismo franquistas (ideologías subyacentes), retrasa el inicio de la decadencia al reinado de Felipe III, con el que «España comenzó a declinar en su grandeza imperial», salvando así el mito de Felipe II y su defensa del catolicismo; liquida el apartado relativo a las causas de la decadencia (expulsión de judíos y moriscos, absolutismo y centralización, guerras). Conserva, en cambio, la valoración positiva de los Borbones (promoción de la agricultura, comercio, educación), si bien, como veremos, acentúa la valoración negativa de la expulsión de los jesuitas. ${ }^{19}$

Las tres ediciones coinciden en considerar que la Guerra de la Independencia "demostró el gran patriotismo del alma nacional», pues cada español fue "un soldado dispuesto a sacrificarse por la patria»: es un nuevo mito de resistencia. La edición de 1953 que, como casi todos los manuales franquistas, reproduce este mito inventado por la historiografía liberal-moderada, da a la guerra de 1808 un nuevo significado: su paralelismo con el «fervor patriótico» de la guerra de 1936. Las tres ediciones igualmente terminan su narración de la historia de España en un tono triunfalista sobre el "progreso material» contemporáneo, si bien la edición franquista localiza más ese progreso, que llama «progreso nacional», en el franquismo. ${ }^{20}$

En esencia, la edición de 1927 responde a un españolismo de raigambre liberal-conservadora, que combina mitos de carácter, antigüedad

\footnotetext{
19 José Dalmáu Carles, Enciclopedia (1927), 419-422 y 424-426, Enciclopedia. (1936), 371-374 y $377-$ 378 y Enciclopedia (1953), 363-365 y 368.

20 José Dalmáu Carles, Enciclopedia (1927), 431 y 445-447, Enciclopedia (1936), 383 y 398-399, y Enciclopedia (1953), 374 y 391-392.
} 
(celtíberos, visigodos como primer Estado), de resistencia (Reconquista), de decadencia (los Austrias: absolutismo y centralismo) y nuevos mitos de resistencia (Guerra de Independencia), con otras ideologías subyacentes: catolicismo, catalanismo, idea de progreso. La edición de 1936 no introduce cambios: el régimen republicano permite la polifonía, la convivencia de versiones distintas del nacionalismo: liberal, republicano, nacional-católico. La edición de 1953, sin dar un giro radical en sentido contrarrevolucionario (mantiene el mito del «progreso») o integrista (no convierte España en brazo armado de Dios), refuerza la visión unitaria de la Reconquista (mapas que separan nítidamente la España cristiana y Al-Andalus) y de los Reyes Católicos (ideología subyacente falangista); elimina la nostalgia foralista (sucesos de 1591, 1640, 1714, 1876); retrasa la decadencia al siglo XVII para salvar el mito de Felipe II; subraya la identidad católica de España y marca paralelismos entre las guerras de 1808 y 1936. Para Ramón López Facal, ${ }^{21}$ la versión liberal y nacional-católica del nacionalismo español coinciden, entre otras cosas, en el organicismo y el historicismo: por eso sigue sirviendo en 1953 la estructura general del relato de las ediciones anteriores.

\section{La ausencia del referente europeo y el sentimiento de Hispanidad}

Los programas y manuales de Historia del primer franquismo no refuerzan la identidad europea. ${ }^{22}$ Pero la Historia de España que se enseñaba a los alumnos de Educación Primaria antes de 1936 también carecía de referente europeo. Dalmau Carles no es una excepción: en las páginas de Geografía, Europa es una suma de Estados; en las de Historia, el lugar de que proceden los bárbaros con los que «retrocedió la cultura de los españoles», aunque los visigodos fueran "la raza menos salvaje» de los mismos; el latín no es una lengua europea sino «nacional»; las guerras europeas de la Edad Moderna se ven desde una perspectiva triunfalista: Gonzalo Fernández de Córdoba «arrojó a los franceses» de Nápoles; con Carlos I, «España fue la primera nación del mundo»; Felipe II «supo sostener la causa del Catolicismo en Europa»; con Felipe V «España volvió

\footnotetext{
${ }^{21}$ Ramón López Facal, «El nacionalismo español en los manuales de Historia», Educació i Història. Revista d'Història de l'educació, 2 (1995): 125.

22 José María Hernández Díaz, ««A Dios gracias, África empieza en los Pirineos». La negación de Europa en los manuales escolares de la España de posguerra, 1939- 1945», Historia de la Educación, 20 (2001): 369-392.
} 
a figurar entre las naciones europeas de primer orden». La cultura española del siglo XVIII no se integra en el marco europeo de la Ilustración. La ausencia de un referente europeo no sólo tiene que ver con el nacionalismo político, sino con el económico, con el proteccionismo imperante. En la edición de 1936 no hay cambios. La edición de 1953, sin embargo, introduce matices significativos: obvia los saqueos «de templos y palacios» realizados por las tropas de Carlos V en Roma, acción impropia de un rey católico, y habla genéricamente de "saqueo» de la ciudad; ya no habla de «venganza» de Felipe II contra Inglaterra, simplemente Felipe «estaba molesto» con este país por su apoyo a Holanda; suaviza el dramatismo con que las anteriores ediciones abordaban la guerra de Flandes limitándose a señalar que fue una "guerra larga y sangrienta». ${ }^{23}$ Es decir, justifica más claramente la política europea de los Austrias y aminora sus consecuencias negativas. Los manuales de Historia del momento refuerzan el proyecto europeo de los Austrias para legitimar no sólo el nacionalismo y el proteccionismo, sino la autarquía y el aislamiento internacional del régimen. Sólo con la tecnocracia y el desarrollismo se critica ese proyecto (ruina, aislamiento) y se recupera de algún modo la visión liberal. ${ }^{24}$

El sentimiento de la Hispanidad dibuja un trazado inverso. Las ediciones de 1927 y 1936 satisfacen el orgullo patrio con referencias al «puñado de valientes» conquistadores, la «pacífica posesión de la América del Sur y las admirables leyes de Indias en favor de aquellas razas indígenas». ${ }^{25}$ La edición de 1953, además de aludir al «Destino Imperial de la Patria», añade párrafos del siguiente tenor:

El gran Imperio Español. Nuestra Patria, después de las conquistas de sus gloriosos marinos y soldados, fue eje y centro del mayor Imperio que ha existido sobre el planeta; España no se lanzó a estas conquistas impelida por egoísmos comerciales ni afanes de dominación; el Emperador y la Nación sentían hondamente las directrices que dejaron consignadas los Reyes Católicos y su

23 José Dalmáu Carles, Enciclopedia (1927), 383, 385, 415, 417, 419, 424 y 430; Enciclopedia (1936), 335, 337, 367, 369, 371, 376 y 382, y Enciclopedia (1953), 327, 329, 361, 363, 358, 368 у 373.

${ }^{24}$ Emilio Castillejo, Mito, legitimación y violencia simbólica en los manuales escolares de Historia del franquismo, 1936-1975, (Madrid: UNED-Serie MANES, 2008), 379-387.

25 José Dalmáu Carles, Enciclopedia... (1927), 415 y 423, Enciclopedia (1936), 367 y 375. 
noble afán era cristianizar todos los pueblos del mundo y llevarles la floreciente cultura de España.

A los conquistadores les seguía una legión de profesores y religiosos misioneros cuya ruda e ímproba labor reconocen y agradecen todos los países que integraron nuestro gran Imperio; hoy estos países, políticamente independientes, conservan con orgullo nuestra lengua y nuestros credos, se honran calificándose de países hispanos y ven en España la madre y autora de su cultura y florecimiento. El Código de Indias, que España dictó para regir sus colonias, se considera como el mejor que se ha estructurado, por su sentido humano y paternal. La Nueva España instaura y fomenta esas relaciones espirituales con los países de su Imperio mediante la magnífica obra del Consejo de la Hispanidad. ${ }^{26}$

El autor se aferra al léxico falangista («Destino Imperial») y nacional-católico (finalidad religiosa del Imperio), en mezcolanza con elementos afectivos (comunidad de sentimientos entre el Emperador y la Nación, alusión a la «madre» España, «Nuestra Patria», "nuestra lengua y nuestros credos») y la legitimación del régimen franquista: el Consejo de la Hispanidad actualiza el Imperio. Antes de la Guerra Civil, la literatura más reaccionaria, temerosa del presente y de la revolución social, quiso hallar cobijo en esa supuesta comunidad espiritual, convertida en auténtica utopía retroactiva (Ramiro de Maeztu). Desde 1939, como es conocido, la Hispanidad es el referente internacional del régimen franquista, aislado y en plena autarquía.

\section{CULTURA POLÍTICA Y CIUDADANÍA}

Siguiendo a Gabriel A. Almond y Sidney Verba, cultura política es el conjunto de creencias, sentimientos, juicios, valores y normas relativos al sistema político que se transmiten al individuo. Estos autores distinguen una cultura parroquial, reacia a un poder central; la cultura del súbdito, propia de sistemas autoritarios, que espera del individuo una actitud pasiva; y la cultura de la participación, propia de las democracias. Estos tipos de cultura no son compartimentos estanco, pueden convivir en un mismo espacio de socialización: cultura parroquial de súbdito, parro-

\footnotetext{
26 José Dalmáu Carles, Enciclopedia (1953), 358-359.
} 
quial-participante, de súbdito participante. ${ }^{27}$ La cultura política integra valores de distinto signo.

\section{Valores políticos: constitución histórica, liberalismo y republicanismo}

La Edad Media sirve para transmitir una visión concreta de las Cortes y la Monarquía. Dalmau Carles elabora, como es tradición tanto en la historiografía escolar nacional-católica como liberal, una historia del poder, de las elites, de cuyas virtudes y defectos depende la prosperidad o decadencia patrias: es la historia que corresponde al modo de educación tradicional-elitista. Es la «historia hegemónica», el reverso de la «historia contrahegemónica», la historia de la gente. ${ }^{28}$ La edición de 1927 parece fiel a un liberalismo conservador de raíz jovellanista, que insiste en el respeto a la constitución histórica, es decir, a instituciones previas al Estado liberal: Cortes, Monarquía, catolicismo. Por eso idealiza las Cortes medievales (para el político e historiador Cánovas del Castillo, el principio de libertad), que ve como la representación de la nobleza, el clero y «el pueblo».

Dalmau Carles también legitima la Monarquía (para Cánovas, el principio de autoridad), con argumentos que nada tienen que ver con el liberalismo o la cultura de la participación, sino con la del súbdito. Entre la Monarquía electiva y hereditaria, prefiere ésta última. Por eso afirma que «Suintila fue un buen rey; quiso convertir en hereditaria la corona de los godos», pues la monarquía electiva «había sido continuo semillero de ambiciones y crímenes». Legitima a los monarcas fuertes, siempre que no caigan en la arbitrariedad o la venganza. Es el matiz que sirve para juzgar a Pedro el Cruel: fue "hombre de carácter impetuoso y colérico, que tomó horribles venganzas contra sus enemigos», aunque muchos «le juzgan como un modelo de justicia y rectitud». A muchos monarcas, ocultando siempre la violencia, se les atribuye estas dos virtudes: Wamba «gobernó con energía y

${ }^{27}$ Gabriel A. Almond y Sidney Verba, «La cultura política», en Diez textos básicos de Ciencia política, ed. Albert Batlle (Barcelona: Ariel, 1992), 171-190. Véase también Giacomo Sani, «Cultura política», en Diccionario de política, a-j, dirs. Norberto Bobbio, Nicola Matteucci y Gianfranco Pasquino (Madrid: Siglo XXI editores, 1991), 415-417.

${ }^{28}$ Ramón López Facal, «Enseñar la historia de la gente», en Historia y proyecto social, ed. Josep Fontana (Barcelona: Crítica-Universitat Pompeu Fabra, 2004), 295-296. 
honradez»; Carlos III de Navarra, con «rectitud» y tuvo «fama de justiciero». El contramodelo es Enrique IV de Trastámara, hombre de "poco carácter», o Rodrigo, que «descuidó los intereses de la nación».

Legitima igualmente el militarismo (Jaime I «es uno de los soberanos más grandes de nuestra Historia: conquistó las islas Baleares, invadió el reino de Valencia»), especialmente si acarrea el sacrificio: Ramiro I de Aragón «murió gloriosamente» en Graus. Si la guerra se ve al margen de la violencia, la labor de los monarcas, al margen de consideraciones sociales: con Fernando III, "la monarquía castellana llegó a un alto grado de esplendor». Al no distinguir fueros locales y territoriales, presenta todos ellos como concesiones reales que «limitaban el poder de los señores feudales y fueron el origen de las futuras libertades»; los Usatges, recopilación de los usos del «pueblo catalán», contribuyeron a «debilitar el poder de los señores feudales». Y legitima la religiosidad: Fernando III «fue muy piadoso; la Iglesia le declaró Santo». Puede valorarse la tolerancia de los monarcas no cristianos como Abderramán III y Alhakén II, «muy tolerante[s] con los cristianos». La intolerancia se evidencia si la víctima es católica (Hermenegildo, "convertido al catolicismo», «sufrió martirio»); pero puede justificarse, al menos implícitamente, la realizada por reyes católicos: Sisebuto «fue muy religioso, y publicó un decreto expulsando a los judíos».

En la nobleza se exalta el heroísmo y la fidelidad: Guzmán El Bueno prefirió la muerte de su hijo a entregar Tarifa «a los enemigos de su rey». En los conflictos nobleza-monarquía, Dalmau Carles se posiciona a favor de ésta, sea por la defensa de la unidad del Estado o por veleidades anti-nobiliarias: justifica a Ramiro II de Aragón que, según la tradición de La campana de Huesca, "hizo decapitar a los [nobles] más revoltosos», colocando sus cabezas en una bóveda a manera de campana, "para que el escarmiento sonara mucho». ${ }^{29}$

La edición de 1936 conserva la misma redacción: no se adapta, por tanto, a la cultura política definida por la Constitución de 1931, que no reconoce elementos prepolíticos previos a la instauración del Estado republicano (monarquía, religión). ${ }^{30}$ Más coherente es que la edición de 1953 asuma íntegramente esa redacción: elitismo, carisma, catolicis-

\footnotetext{
29 José Dalmáu Carles, Enciclopedia (1927), 387-388, 392-393 y 400-409.

30 José Dalmáu Carles, Enciclopedia (1936), 339, 344-345 y 350-362.
} 
mo, militarismo, opinión negativa de la nobleza levantisca, figura de los partidos políticos, Cortes, idealizadas tanto por el liberalismo como por el tradicionalismo, conjugan muy bien con la cultura política franquista. Sólo hay alguna modificación significativa: añade un grabado inspirado en el pintor historicista romántico Antonio Muñoz Degrain sobre la conversión de Recaredo, para reforzar uno de los mitos más queridos por la Iglesia; elimina la referencia a que los fueros son «el origen de las futuras libertades», mito estrictamente liberal. ${ }^{31}$

Sobre la Edad Moderna, Dalmau Carles comparte otro mito liberal: la crítica a los Austrias por el «absolutismo y la centralización, que ahogaron las iniciativas individuales y mataron la vida de las regiones», y porque disminuyeron el poder de las Cortes. Mito que casa con el catalanismo y con la atribución de la sublevación de los comuneros a «la desconsideración» de Carlos I, que no atendió las peticiones de las Cortes frente a «los ambiciosos flamencos»: la decapitación convierte a los comuneros en mártires de las libertades. Tampoco merecen una valoración positiva los Borbones por abolir los fueros y «prescindi[r] totalmente de las Cortes». Pero sigue justificando valores ajenos al liberalismo. Primero, el catolicismo: legitima implícitamente la intransigencia religiosa cuando afirma que Felipe II «conserv[ó] en España la paz de las conciencias», y crítica la expulsión por Carlos III de la Compañía de Jesús, «que ha producido tantos hombres eminentes», aunque recuerde que también se les expulsó de otros países y que los jesuitas más tarde pudieron volver. Segundo, el nacionalismo y el imperialismo: critica las «guerras desastrosas» de los Austrias por soñar "en el dominio del mundo», pero subraya que con Carlos I, «España fué la primera nación del mundo». Tercero, el carisma de los gobernantes: Cisneros «es una de las figuras más ilustres de nuestra Historia, por su sabiduría y grandes dotes de gobernante»; Felipe V, "un soberano ilustrado y amante de la cultura y el pueblo»; Fernando VI, «uno de los monarcas más buenos, nobles y pacíficos». Los contramodelos carecen de carisma: Felipe III, Felipe IV, Carlos II o Carlos IV carecían «de las condiciones necesarias para gobernar». Los monarcas son tan determinantes que se confunde Corte y sociedad:

Las costumbres. En tiempos de Carlos I, predominaron la ostentación y la magnificencia; durante el reinado de Felipe II, dominó

31 José Dalmáu Carles, Enciclopedia (1953), 330-331, 335 y 342-353. 
una gran austeridad; después las costumbres se relajaron de tal modo, que el trabajo manual era tenido como una deshonra, y la vagancia, la miseria, la suciedad imperaban en todas las clases sociales. $^{32}$

La edición de 1936 conserva íntegra esta redacción, por tanto sus valores (elitismo, monarquismo, catolicismo, militarismo,...) no casan con la cultura política de la participación o el laicismo republicanos. ${ }^{33}$ En la edición de 1953 únicamente desaparece el mito liberal sobre los comuneros: no habla de decapitación, sino de derrota, y no aduce como causa de su sublevación la «desconsideración» de Carlos I, sino que «el pueblo español» «no comprend[ió] el plan que el monarca emprendía bajo la ruta que impone el Destino Imperial de España»: un mito muy querido de Falange. Hay, además, una vuelta de tuerca en el austracismo, como en todos los manuales del momento. Elimina la referencia a las causas de la decadencia de los Austrias (expulsión de minorías, crisis demográfica, absolutismo, centralización, guerras,...), y, aunque cite que las Cortes se reunían «de tarde en tarde», no recuerda que «los diputados tenían más limitada su libertad». Y, aunque siga aludiendo al "progreso material» de los Borbones, acentúa el dramatismo de la expulsión de los jesuitas: ya no refiere que la expulsión se produjo también en otras partes, exculpa a los jesuitas de participar en el motín de Esquilache y avanza consecuencias nefastas según el canon contrarrevolucionario:

Expulsión de los jesuitas (1767). Habiéndose atribuido a los jesuitas — tal vez a sugerencia de Aranda- el ser instigadores del motín de Esquilache -lo cual, naturalmente no pudo comprobarse- y receloso el rey del prestigio que adquiría la Compañía de Jesús, fundada por San Ignacio de Loyola, por haber producido tantos hombres eminentes y poseer gran influencia, decretó su expulsión y confiscación de bienes. Esta injusta medida fue uno de los primeros síntomas de la infiltración en España de las ideas revolucionarias y afrancesadas. ${ }^{34}$

\footnotetext{
32 José Dalmáu Carles, Enciclopedia (1927), 422. Información anterior, páginas 413-415, 419-420, 422, 425-426 y 428.

33 José Dalmáu Carles, Enciclopedia (1936), 366-367, 371, 374-375 y 377-380.

34 José Dalmáu Carles, Enciclopedia (1953), 369-370. Información anterior, 358 y 366-367.
} 
La inclinación liberal de las páginas de Historia Contemporánea de la edición de 1927 es clara. Identifica a Fernando VII con «ingratitudes, torpezas, persecuciones y horrores que contribuyeron a empobrecer la $\mathrm{Pa}$ tria y a detener su civilización»; habla del "martirio» de Riego; explica los josefinos por el «conocimiento que tenían de lo que la Patria podía esperar de Fernando VII»; identifica carlismo y absolutismo; refiere «los grandes progresos materiales» del periodo contemporáneo. Pero sigue legitimando la constitución histórica. Hay una vinculación afectiva con la Monarquía borbónica: con Alfonso XII, cuyo «reinado fue de paz y amor, dedicado por entero al bien y la prosperidad de la Patria»; con M. ${ }^{a}$ Cristina de Habsburgo, «modelo de previsión y sabiduría» y con Alfonso XIII y Victoria Eugenia, víctimas de un atentado en que resultaron ilesos "por puro milagro". La vinculación con el catolicismo se expresa presentando el anticlericalismo como un fenómeno violento al margen del contexto social, en que la Iglesia es sólo víctima: la matanza de frailes en 1835; las «medidas radicales» de los progresistas (desamortización, supresión del diezmo); la Semana Trágica de 1909, «que dirigió todos sus ataques a conventos e iglesias».

Dalmau Carles se identifica con el liberalismo doctrinario o moderado de la época de Isabel II (Narváez dictó leyes «que constituyeron una gloria del partido moderado»: la Guardia Civil «acabó con el bandolerismo»), o con la Restauración: Cánovas y Sagasta «trabajaron con Alfonso XII para conseguir el resurgimiento de la Patria». Entiende menos los "graves disturbios» republicanos en tiempos de Amadeo I y la Primera República, en que «los valores públicos bajaron extraordinariamente». No extraña que elogie el "gran patriotismo y desinterés» de Emilio Castelar al hacerse cargo de la Presidencia de la República o legitime el golpe de Martínez Campos «de acuerdo con valiosos personajes militares y civiles». ${ }^{35}$ Los manuales de Historia tienen tendencia irreprimible a consolidar el presente. Pero, dado que este manual de 1927 no ha revisado su redacción, ${ }^{36}$ el presente que legitima no es la Dictadura de Primo de Rivera, sino la Restauración:

Confianza en el porvenir. El estado social angustioso creado por la tremenda guerra europea y las sangrientas campañas de Ma-

\footnotetext{
35 José Dalmáu Carles, Enciclopedia (1927), 433-455.

${ }^{36}$ Aunque el R.D. de 23 de agosto de 1926 pretendía el libro único editado por el Estado, debido a la oposición de familias, del profesorado y de las editoriales sólo en 1928 y 1929 se designan libros oficiales de bachillerato: Manuel de Puelles Benítez, «La política del libro escolar en España, 1813-1939», en Historia ilustrada del libro escolar en España. Del Antiguo Régimen a la Segunda República, 63.
} 
rruecos, inspirarán sin duda a nuestro soberano [Alfonso XIII] cuanto conviene a los sagrados intereses de la Nación. En ello confían todos los españoles, que conocen su patriotismo y hacen votos por una España pujante y venturosa». ${ }^{37}$

De hecho, sus páginas de Derecho legitiman el entramado institucional de la Constitución de 1876, que en 1927 se hallaba en suspenso. ${ }^{38}$

La edición de 1936, para legitimar la Segunda República, elimina las referencias a la confianza que parecía generar Alfonso XIII, añade que éste se desligó de su condición de rey constitucional al confiar el poder a un dictador y afirma que las elecciones de abril de 1931 expresaron la protesta por «la pérdida de las libertades» y la República se proclamó «en medio de un entusiasmo muy grande y sin que se produjera ningún desmán». ${ }^{39}$ Pero la legitimación del nuevo régimen resulta fragmentaria y contradictoria: legitima su origen, pero no sus valores. Las páginas de Historia conservan la misma redacción y valores monárquicos. Las de Derecho y de Moral Cívica legitiman el entramado institucional de Segunda República (Constitución de 1931, derechos políticos, autonomías,...) y consideran deber del ciudadano respetar autoridades y leyes vigentes. Pero conservan expresiones de las ediciones anteriores muy alejadas del espíritu de la Carta Magna de 1931: el matrimonio es contrato y sacramento que obliga al marido «a trabajar para el sostenimiento de su esposa» y a la mujer "a seguir a su marido a donde éste se establezca, a obedecerle, a no enajenar sus bienes»; la propiedad como derecho absoluto no subordinado a la utilidad social como afirma el art. 44 de la Constitución de 1931. Y evita referencias a los derechos sociales y al Estado laico. ${ }^{40}$ No socializa a los alumnos en los valores republicanos.

La edición de 1953 conserva los valores católicos y antirrepublicanos de las ediciones anteriores: casan muy bien con el franquismo. Pero debe borrar al máximo la huella liberal. Para tal fin, suaviza la represión de Fernando VII (no habla de mártires liberales), no identifica al carlismo con el absolutismo, sino con la reintegración de España «a sus esencias

\footnotetext{
37 José Dalmáu Carles, Enciclopedia (1927), 445. Resto información, 433-455.

38 José Dalmáu Carles, Enciclopedia (1927), 618-627.

39 José Dalmáu Carles, Enciclopedia (1936), 384-397.

40 José Dalmáu Carles, Enciclopedia (1936), 566, 570-572, 576-581, 596-597 y 614-616.
} 
tradicionales» frente a «los exagerados progresos liberales»; elogia la política de orden de Narváez, pero obviando que los moderados eran un partido político; ya no son Cánovas y Sagasta los que trabajaron para regenerar España, sólo Cánovas; Alfonso XIII ya no se desdice de su juramento constitucional; la Dictadura de Primo de Rivera, «años de paz y gran prosperidad», pretendió «encauzar la vida política de España». Deslegitima la Segunda República por su origen (llegó «con el pretexto de unas elecciones municipales») y ejercicio, que explica que surgiera Falange "para oponerse a la revolución roja que se avecinaba» y el «Movimiento Salvador de España, acaudillado por el invicto Generalísimo don Francisco Franco»:

De 1931 a 1936, la Segunda República española siguió en su actuación una marcha peor que la primera; la labor sectaria iba hundiendo poco a poco todos los valores espirituales y sociales de nuestra patria. Para colmo, las más audaces teorías disolventes fueron entronizadas en nuestro país y se desataron todas las violencias, siendo numerosos los patriotas que cayeron gloriosamente víctimas de tal ferocidad; debemos destacar entre ellos la figura del eminente político don José Calvo Sotelo. ${ }^{41}$

La edición de Dalmau Carles de 1927 legitima el régimen oligárquico y liberal-moderado de Isabel II (Narváez) y conservador de la Restauración. La edición de 1953 añade la legitimación de la vieja extrema derecha (los carlistas ya no son absolutistas) y las nuevas extremas derechas (primorriveristas, falangistas). Como el resto de manuales de Historia del franquismo, concilia las trayectorias históricas de las fuerzas de la coalición vencedora en la Guerra Civil: monárquicos alfonsinos, primorriveristas, carlistas, falangistas, militares. Así actúa también el dictador.

Las páginas de Derecho de la edición de 1953 legitiman el franquismo: la misión del Estado Español es recuperar «el sentido profundo de una indiscutible Unidad de Destino y la fe resuelta en su misión católica e imperial»; el Jefe del Estado "asume la dirección del poder»; las Cortes, integradas por «altas personalidades de la Nación», asesoran al Gobierno; el Partido Único es el «enlace entre el Estado y la Sociedad»; el Esta-

${ }^{41}$ José Dalmáu Carles, Enciclopedia (1953), 388-389. Información anterior, 377-388. 
do Nacional-Sindicalista integra los elementos de la producción «desde un punto de vista nacional y cristiano, suprime la lucha de clases». ${ }^{42}$

La cultura política de la edición de Dalmáu Carles de 1927 quizás encaje bien con la cultura del súbdito participante que definían Almond y Verba: habla de elecciones, pero inculca la lealtad a Alfonso XII, Alfonso XIII, Cánovas y Sagasta, que solucionan los problemas. Su concepto de ciudadanía es a la vez liberal (rechaza el absolutismo por impedir el desarrollo del individuo) y comunitarista: respeto a la comunidad de memoria o constitución histórica. La edición de 1936 no inculca un concepto republicano de ciudadanía basado en la participación y la democracia deliberativa, ni recuerda que la Constitución de 1931 contiene derechos sociales y anuncia la intervención del Estado para impedir el sometimiento de los más débiles (libertad como no-sometimiento): del ciudadano de la República sólo se espera obediencia a las leyes. ${ }^{43}$ La redacción de 1953 elimina toda reminiscencia liberal: sólo cabe esperar que los súbditos españoles se sumen al Destino Universal de la Patria.

\section{Valores sociales: visión armónica de la sociedad y corporativismo}

La cultura política integra también valores sociales. Las páginas de Economía, Derecho y Educación Social de las ediciones de 1927 y 1936 defienden la propiedad en un sentido absoluto, «no sólo contra los atropellos de los particulares sino contra un posible abuso por parte de las autoridades», y sólo prevén expropiaciones forzosas por la realización de obras públicas. Esta definición liberal de propiedad no se aviene con la que da la Constitución de 1931. La edición franquista de 1953, en cambio, afirma que el derecho a la propiedad «queda supeditada al interés público y social»: ${ }^{44}$ la misma simulación hace Falange (revolución pendiente) y la Iglesia, para la que los bienes de Dios son administrados por los ricos. Las instituciones capitalistas son definidas, con benevolencia, por su función: los bancos «fomenta[n] el desarrollo del comercio, facilitando la circulación de los capitales y regularizando el crédito»; las socie-

42 José Dalmáu Carles, Enciclopedia (1953), 559-569.

43 Sobre esos modelos de ciudadanía: Javier Peña, «La ciudadanía», en Teoría política: poder, moral, democracia, eds. Aurelio Arteta, Elena García Guitián y Ramón Máiz (Madrid: Alianza, 2003), 236243; Philip Pettit, Republicanismo. Una teoría sobre la libertad y el gobierno (Barcelona: Paidós, 1999).

44 José Dalmáu Carles, Enciclopedia (1927), 619, Enciclopedia (1936), 571, y Enciclopedia (1953), 573. 
dades mercantiles «juntan sus capitales» para explotar un negocio. ${ }^{45} \mathrm{La}$ separación capital-trabajo es justificada en las ediciones de 1927 y 1936 como un fenómeno natural:

Elementos de producción. En toda explotación industrial intervienen tres elementos distintos: el capital, el cual es aportado por una o varias personas; la dirección de un negocio, a cargo de un gerente o de un consejo de dirección, y el trabajo, o sea el conjunto de operarios que realizan las distintas labores de la industria en cuestión. ${ }^{46}$

La edición de 1927 legitima con evidente conformismo el sistema de protección social de la Restauración (Ley de accidentes, Ley de huelgas). No cambia la redacción de la edición de 1936, que no legitima, por tanto, la legislación social republicana, pero sí la de 1953, para legitimar las leyes sociales del franquismo. ${ }^{47}$

La institución matrimonial, para las tres ediciones sacramento y contrato entre cónyuges, justifica los roles del hombre y de la mujer y la obediencia de ésta al marido. ${ }^{48}$ También desde una perspectiva católica, las tres ediciones inculcan el «sacrificio» llevado con "generosidad y contento", el trato a las personas «de manera distinta según sea su edad, su sexo y su rango o calidad». No carece de contenido social insistir en la paciencia para «sufrir» las flaquezas de los demás, el sacrificio por la $\mathrm{Pa}$ tria, la compostura en el templo, la sobriedad, evitar los espectáculos que atenten "contra la moral» y al amigo "díscolo o revoltoso». ${ }^{49}$ Normas de urbanidad que significan, en términos de Michel Foucault, el control de los cuerpos. ${ }^{50}$ Las ediciones de 1936 y 1953 añaden unas páginas de Moral Cívica con referencias al robo («vivamos con austeridad, pero con la

45 José Dalmáu Carles, Enciclopedia (1927), 599-600 y 608, Enciclopedia (1936), 551-552 y 560, y Enciclopedia (1953), 545 y 554.

46 José Dalmáu Carles, Enciclopedia (1927), 630, y Enciclopedia (1936), 582.

47 José Dalmáu Carles, Enciclopedia (1927), 630-631, Enciclopedia (1936), 582-583, y Enciclopedia (1953), 562, 567-568 y 593.

48 José Dalmáu Carles, Enciclopedia (1927), 614-616, Enciclopedia (1936), 566-568, y Enciclopedia (1953), 569-571.

49 José Dalmáu Carles, Enciclopedia (1927), 633-642, Enciclopedia (1936), 585-594, y Enciclopedia (1953), 577-586.

${ }^{50}$ Michel Foucault, Microfísica del poder (Madrid: Ediciones La Piqueta, 1992), 148-151. 
conciencia limpia»), a la paz social según la entiende la doctrina eclesial: que dirigentes y trabajadores «sientan, satisfechos, su condición de tales, y se completen y estimen como partes que son de una misma actividad», pues «un régimen de mutuo amor es mucho más apropiado para resolver con mayor eficacia y justicia las cuestiones sociales, que las actitudes intransigentes y violentas». ${ }^{51} \mathrm{El}$ corporativismo, de hecho, es compartido por la Iglesia y distintas tradiciones derechistas, incluido el catalanismo de Enric Prat de la Riba, Francesc Cambó, o Eugenio d'Ors antes de evolucionar hacia el falangismo. ${ }^{52}$ La misma órbita dibuja Dalmau Carles, que olvida el catalanismo, pero no el corporativismo.

El efecto de estos valores (propiedad, corporativismo, resignación, frugalidad, patriotismo) es la reducción de las contradicciones sociales a la mínima expresión. Al margen de regímenes políticos, las páginas de Historia de todas las ediciones de Dalmau Carles ocultan esas contradicciones. En primer lugar, con una expresión triunfalista en que los adjetivos y pronombres inclusivos sirven tanto para evidenciar la continuidad de la nación como para ocultar la posesión de bienes materiales (en tiempos de Roma, «nuestro aceite» era «el mejor del mundo») y de bienes culturales: en el Califato de Córdoba, «la cultura del pueblo fue tan general, que era raro hallar un hombre que no supiera leer y escribir». ${ }^{53}$

En segundo lugar, reafirma valores sociales y culturales como el sexismo, aunque sea simulando avances sociales: «Los godos dignificaron a la mujer en gran manera, considerándola en lo que merece por su debilidad y como esposa y madre». ${ }^{54}$

En tercer lugar, exalta la prosperidad que procuran ciertos poderes (cultura política del súbdito), olvidando a las clases productoras: los reyes de León o Fernando III proporcionaron «riqueza pública», los Borbones ennoblecieron el trabajo, "considerándolo justamente como fuente de dignidad y riqueza»: son así referente del homo economicus burgués. Muestra conformidad con los «grandes adelantos materiales» de la épo-

\footnotetext{
${ }^{51}$ José Dalmáu Carles, Enciclopedia (1936), 601-602 y 611-612, y Enciclopedia (1953), 593 y 601-602.

52 Pedro Carlos González Cuevas, Historia de las derechas españolas. De la Ilustración a nuestros días (Madrid: Biblioteca Nueva, 2000), 204-210.

53 José Dalmáu Carles, Enciclopedia (1927), 382-383 y 391, Enciclopedia (1936), 334-335 y 343, y Enciclopedia (1953), 327 y 333.

${ }^{54}$ José Dalmáu Carles, Enciclopedia (1927), 389, Enciclopedia (1936), 341, y Enciclopedia (1953), 332.
} 
ca de Isabel II o de la Edad Contemporánea, si bien la edición de 1953 añade referencias a la «gran prosperidad» de la Dictadura de Primo de Rivera y al «progreso nacional» (no «material») franquista. La obra social del poder se define con criterios historiográficos más que dudosos que, de nuevo, borran la jerarquía social: los visigodos «establecieron la igualdad de todos los hombres ante la ley», el Código de los Usatges de Ramón Berenguer I debilitó «el poder de los señores feudales», los Austrias aprobaron «las admirables leyes de Indias en favor de aquellas razas indígenas». .5

En cuarto lugar, las descripciones de la sociedad, atentas a la función de cada grupo social (según el canon elitista, organicista y corporativo), olvidan la posesión. La descripción de la sociedad feudal, por ejemplo, responde a un planteamiento liberal: el feudalismo no es modelo de equilibrio (al contrario que para la contrarrevolución), pero apenas contiene contradicciones sociales. Una redacción perfectamente asumible por la edición franquista. Señala que esa sociedad integra diversas «instituciones»: la Monarquía, la Iglesia, la Nobleza y el Pueblo, «constituido por la masa general de los ciudadanos, que se llamaban siervos o villanos: trabajaba la tierra y debía hallarse constantemente a la disposición de los señores». Y añade:

El feudalismo. La tierra se hallaba dividida en villas, que venían a ser lo que ahora son los municipios, y pertenecía a los señores. Los señores eran dueños de las vidas y haciendas de los villanos, y su poder era tan extraordinario, que muchas veces se rebelaban contra el mismo rey: esta organización social se llamaba feudalismo.

La propiedad. Había tres clases de propiedad: de realengo, o del monarca: de abolengo, o de la Iglesia, y de solariego, o de los nobles.

Las contribuciones. La nobleza y el clero no pagaban contribuciones: los villanos o siervos debían pagar todos los impuestos y

55 José Dalmáu Carles, Enciclopedia (1927), 389, 398, 401, 406, 423, 430, 437, 443 y 446, Enciclopedia (1936), 341, 350, 353, 358, 375, 382, 389, 395 y 398, y Enciclopedia (1953), 332, 340, 348, 349, 366, $372,381,386,388$ y 391. 
otras contribuciones especiales que a menudo imponían el clero y la nobleza. ${ }^{56}$

Términos como «instituciones» o «ciudadanos», o la afirmación de que el "pueblo» estaba representado en las Cortes, minimizan las escasas contradicciones que plantea. La única rebelión que cita es la de los nobles contra los reyes, no las de las clases populares: el poder preocupa más que la estructura social. Cuando describe la sociedad de la época de los Austrias, el feudalismo, como corresponde a un planteamiento liberal, se ve como una rémora: «La propiedad, efecto del feudalismo [...], era patrimonio de pocos», "pesando sobre el pueblo todos los impuestos»: un pasado superado permite confirmar el presente. Y al confundir la sociedad con las «costumbres» (con los Austrias Menores «el trabajo manual era tenido como una deshonra, y la vagancia y la miseria imperaban en todas las clases sociales»), las estructuras (mentalidad nobiliaria, pobreza,...) se convierten en mera coyuntura. ${ }^{57}$

En quinto lugar, dada la ausencia de contradicciones sociales y la acción bienhechora del poder, carece de sentido el conflicto social. En las escasas ocasiones en que se evidencia es para tergiversar las causas (siempre ocultas), protagonistas y acontecimientos (violencia). Las ediciones de 1927 y 1936 destacan los disturbios provocados en el Sexenio Revolucionario por carlistas y republicanos si bien, dado que los únicos móviles parecen políticos, no averiguamos los motivos sociales de la revuelta como no sea la referencia genérica a las quintas:

Los republicanos se alzaron en armas en Andalucía; los carlistas se levantaron en el Norte; en muchas ciudades ocurrieron sangrientos motines con motivo de las quintas, y la insurrección de Cuba y Puerto Rico, que ya había estallado antes de la revolución, tomó gran incremento. ${ }^{58}$

\footnotetext{
56 José Dalmáu Carles, Enciclopedia (1927), 408-409, Enciclopedia (1936), 360-361, y Enciclopedia (1953), 351-353.

57 José Dalmáu Carles, Enciclopedia (1927), 422, Enciclopedia (1936), 374, y Enciclopedia (1953), 365.

58 José Dalmáu Carles, Enciclopedia (1927), 438, y Enciclopedia (1936), 390.
} 
La edición franquista se limita a eliminar la referencia a los carlistas. ${ }^{59}$ Algo similar ocurre con la «Semana Sangrienta» de 1909, un movimiento "para protestar» por el embarque de tropas (sin más razones), «que se convirtió en revolución que dirigió todos sus ataques a conventos e iglesias»: queda clara la violencia de la revuelta, no sus causas. La edición de 1953 matiza que la revuelta se dio «con el pretexto de protestar del embarque de soldados reservistas», lo mismo que la Segunda República llegó "con el pretexto» de unas elecciones municipales: existe un orden natural de las cosas, las rebeliones contra el mismo derivan sólo de pretextos. ${ }^{60}$

\section{Valores religiosos: sus virtudes nacionales, políticas, sociales y culturales}

La religión no es un fenómeno exclusivamente espiritual, sino que refuerza otros valores mundanos. ${ }^{61}$ La religión sirve a la identidad, al poder político, al orden social y a la Iglesia. La edición de Dalmau Carles de 1927 (con Nihil Obstat e Imprimatur de 1924), en primer lugar, recoge mitos identitarios cercanos al liberalismo conservador: el catolicismo es ingrediente de la nacionalidad, pero la historia nacional no se subordina a la fe, como en el nacionalcatolicismo más ortodoxo. Recoge el mito de la antigüedad del cristianismo en España: Santiago, San Pablo «predicaron en España la salvadora doctrina de Jesús». El mito del martirio de Hermenegildo y la conversión de Recaredo, o de que los visigodos «acabaron con el paganismo» y legaron a España «el Catolicismo». Entiende éste como el aglutinante que une a «godos y españoles» (implícitamente ha hecho la Patria), y habla de "la santa obra de la Reconquista» o lucha «por la religión y por la Patria». Evita los juicios de valor sobre la «unidad religiosa» que pretende la Inquisición, sobre la expulsión de los moriscos, perjudicial en el orden económico, aunque «en el social y político, algunos creen necesaria»; o sobre el hecho de que Felipe II conservó «la paz de las conciencias»: el liberalismo de Dalmau Carles, pusilánime,

\footnotetext{
59 José Dalmáu Carles, Enciclopedia (1953), 381-382.

60 José Dalmáu Carles, Enciclopedia (1927), 445, Enciclopedia (1936), 397, y Enciclopedia (1953), 387-388.

61 Ese refuerzo es el que Weber llama «afinidad»: Max Weber, Sociología de la religión (Madrid: Istmo, 1997), 448
} 
no defiende principios como la libertad religiosa, ni rivaliza con el nacionalcatolicismo más integrista. Pretende convivir con él. La Guerra de la Independencia es una lucha "por la Patria»: se sobreentiende que el catolicismo forma parte de su historia. ${ }^{62}$ Ese sobreentendido es común a muchos manuales, aun del periodo franquista: también muchos sacerdotes sublevados contra el francés olvidaron en sus arengas la referencia a la religión, implícita en sus apelaciones a la Patria y la Monarquía. ${ }^{63}$

La imagen del otro ésta está condicionada también por la religión. Si los visigodos eran «la raza menos salvaje de los bárbaros» es porque antes de llegar a España conocían "algo el cristianismo»; de los árabes se dice que son "astutos, hipócritas y vengativos»; de los judíos, que fueron expulsados por ser "acusados entonces de grandes crímenes», sin especificar el origen de estos bulos. Una mentalidad finalista implica que explique la batalla de Lepanto porque España, Roma y Venecia estaban «alarmados por el poder de los turcos»; las guerras de Felipe II en Flandes, porque el protestantismo «se había extendido en todo el país»; la expulsión de los moriscos, "por haberse descubierto una vasta conspiración». ${ }^{64}$

La edición de 1927 supedita el ideal liberal de la libertad de conciencia a la identidad católica; la edición de 1936, aunque sin Nihil Obstat, repite la redacción anterior contradiciendo así el ideal laico republicano. Por eso, a pesar de no reforzar el nacionalcatolicismo más estricto, la edición de 1953 no necesita cambios, como no sea aligerar la crueldad de la Inquisición: en lugar de señalar que quemó «vivos a gran número de judíos, acusados entonces de grandes crímenes», afirma que «conden[ó] a gran número de judíos». ${ }^{65}$

La religión católica, en segundo lugar, legitima el poder: como sabemos, el catolicismo se entiende como una virtud que legitima a los reyes

\footnotetext{
62 José Dalmáu Carles, Enciclopedia (1927), 383, 389, 396-397, 412, 419 y 430-432.

${ }^{63}$ Emilio Castillejo Cambra, «La función de los mitos sobre «la Guerra de la Independencia» transmitidos a través de la enseñanza de la historia», en Guerra, sociedad y política (1808-1814) I, coord. Francisco Miranda Rubio (Pamplona: Gobierno de Navarra, Departamento de Cultura y Turismo, Institución Príncipe de Viana, Universidad Pública de Navarra, 2008), 162.

${ }^{64}$ José Dalmáu Carles, Enciclopedia (1927), 385, 394, 412, 416-417 y 419, Enciclopedia (1936), 337, 346, 364, 368-369 y 371, y Enciclopedia (1953), 329, 336, 355, 360-361 у 364.

65 José Dalmáu Carles, Enciclopedia (1936), 335, 341, 348- 349, 364, 371 y 382-384, Enciclopedia (1953), 332, 337, 340, 355, 363-364 y 373-375.
} 
(Fernando III, Reyes Católicos, Felipe II), mientras se deslegitiman los regímenes que no respetan la constitución histórica (los Borbones, por la expulsión de los jesuitas, las «medidas radicales» de los progresistas del siglo XIX). La edición franquista, como sabemos también, no hace otra cosa que acentuar ese principio, además de añadir referencias a la Segunda República, síntesis de todos los males.

En tercer lugar, legitima la institución eclesial. La edición de 1927 refleja la idea, común a muchos manuales de Historia, de que la Iglesia es una institución "santa», divina, situada, por tanto, al margen de la sociedad y de la historia, carente de historicidad. Por eso, por ejemplo, la Iglesia queda al margen de la estructura de poder del feudalismo y merece párrafos separados que subrayan su labor cultural:

La Iglesia. La Iglesia ejerció una influencia poderosa en la obra de la Reconquista, porque el sentimiento religioso era, entonces, más grande que el sentimiento patrio; la Iglesia, por otra parte, fue el arca santa que salvó toda la cultura antigua: las letras entonces hallaron en el clero un amoroso guardador. ${ }^{66}$

Se legitiman también personajes ilustres como Isidoro de Sevilla, "admiración del mundo por su virtud y sabiduría», o Cisneros, «una de las figuras más ilustres de nuestra Historia, por su sabiduría y grandes dotes de gobernante»: la Iglesia no es poder y posesión, es saber y virtud. La edición de 1936 no introduce ningún cambio en estos aspectos (no legitima el nuevo espíritu republicano y laico); la de 1953 no necesita añadir nada para adaptarse al nacionalcatolicismo imperante. ${ }^{67}$

Por último, se legitiman los valores propios de la institución eclesial. Valores políticos (la evaluación de un régimen depende en buena medida de su respeto a los privilegios eclesiales), sociales (doctrina social de la Iglesia, concepción católica del matrimonio), culturales (la ecuación Iglesia y «saber») que supone desconsiderar todo saber secularizado: la ilustración (con minúscula) del siglo XVIII se identifica con la creación por los monarcas de escuelas y academias, obviando la pugna eclesial por el monopolio cultural; ninguna referencia a la secularización de la «bri-

66 José Dalmáu Carles, Enciclopedia (1927), 408. Información anterior, 409.

67 José Dalmáu Carles, Enciclopedia (1927), 389 y 413, Enciclopedia (1936), 360-361, 341 y 365, Enciclopedia (1953), 352-353, 332 y 356. 
llante» producción literaria contemporánea. El liberalismo conservador español, respetuoso con la constitución histórica, no sólo se desdice del laicismo político, sino que reniega de sus raíces culturales, la Ilustración. En esto tampoco hay cambios en las ediciones de 1927, 1936 y $1953 .{ }^{68} \mathrm{De}$ igual manera, sus páginas de Historia Natural clasifican los mamíferos o explican las facultades superiores (en comparación con otros seres vivos) del cerebro humano sin ninguna referencia al evolucionismo. ${ }^{69}$

Las páginas de Educación Social de la edición de 1927, como corresponde al sistema educativo de un Estado confesional, recomiendan amar a Dios, «nuestro Criador», exaltan la paciencia y la modestia, «virtud que nos convence de nuestra pequeñez»: ${ }^{70}$ el sentimiento de dependencia y de sumisión y el valor de la jerarquía son consustanciales al fenómeno religioso. ${ }^{71}$ La edición de 1936 añade que «la religión es para el hombre un freno a sus pasiones y a su ambición», ${ }^{72}$ reconocimiento explícito de que no hay ética ni moral al margen de la misma. La edición de 1953, para reafirmar un nacionalcatolicismo militante, amplía este punto con referencias a la falsedad de otras religiones y del ateísmo, pues no se puede «comprender la vida como una pura casualidad», ${ }^{73}$ negación implícita del evolucionismo.

La Historia Sagrada consolida esos valores. La Segunda República estableció la enseñanza laica. Por orden de 12 de enero de 1932, para salvaguardar la conciencia del niño, prohibía en enseñanza primaria toda propaganda política, social o religiosa. Lo mismo ocurrió en el bachillerato ${ }^{74}$ En la edición de 1936 de la Enciclopedia Dalmau Carles, por tanto, no hay ni Nihil Obstat ni Historia Sagrada, lo cual, como estamos viendo, no evita que la propaganda religiosa se cuele en otras páginas. En las

\footnotetext{
68 José Dalmáu Carles, Enciclopedia (1927), 430 y 447, Enciclopedia (1936), 382 y 399, y Enciclopedia (1953), 373 y 392.

69 José Dalmáu Carles, Enciclopedia (1927), 499-500, Enciclopedia (1936), 451-452, y Enciclopedia (1953), 445-446.

70 José Dalmáu Carles, Enciclopedia (1927), 634 y 637-638.

71 Walter Burkert, La creación de lo sagrado. La huella de la biología en las religiones antiguas (Barcelona: Acantilado, 2012), 145-177.

72 José Dalmáu Carles, Enciclopedia (1936), 586 y 588-589.

73 José Dalmáu Carles, Enciclopedia (1953), 578.

${ }^{74}$ Manuel de Puelles Benítez, «Religión y escuela pública en nuestra historia: antecedentes y procesos», Bordón, 58 (2006): 524 y 526.
} 
páginas de Historia Sagrada de las ediciones de 1927 y 1953, no es difícil averiguar, por ejemplo, el valor social de la jerarquía que Dios estableció entre los ángeles, utilizada para legitimar la jerarquía social, de la obediencia de Abrahán, del premio a la resignación de Job. O del significado político del castigo de Dios a los reyes de Israel por su soberbia. O del significado cultural de «la ingratitud de los judíos» a propósito de la Pasión, o del anuncio de que la Iglesia «siempre ha triunfado y triunfará de sus enemigos». La redacción de la edición de 1953, más breve, pretende acomodarse a la precariedad que trae consigo la autarquía (la obediencia de Abrahán, añade, es un «magnífico ejemplo para aquellos que no son capaces de renunciar al más pequeño de sus gustos o afectos por el amor de Dios»); inculcar la obediencia a un régimen autoritario: exhorta, a propósito de la narración de la Presentación en el Templo, a «cumplir las leyes de la Tierra»; refuerza una imagen más violenta de Jesús añadiendo un grabado sobre la expulsión de los mercaderes del templo. ${ }^{75}$

\section{REFLEXIÓN FINAL: EDICIÓN ESCOLAR, RÉGIMEN POLÍTICO Y MODELO EDUCATIVO}

Se ha afirmado muchas veces que los manuales escolares legitiman el régimen político que concibe el plan de estudios al que obedecen. Esta afirmación no puede hacerse sin matices: pueden confluir otras circunstancias. Por ejemplo, que un régimen no elabore su plan de estudios. La Dictadura de Primo de Rivera no introdujo ningún plan nuevo en Primaria, siempre abandonada a su suerte, como no sea la R.O. de 13 de octubre de 1925 sobre «Propagandas antipatrióticas y antisociales». ${ }^{76}$ Por eso la edición de 1927 de Dalmau Carles no legitima la dictadura, sino la Restauración: no desobedece ninguna ley, porque no hay ningún programa que obedecer.

La ideología de esta edición podría resumirse así. En lo económico, defensa de un capitalismo, entendido como un fenómeno natural, matizado por el corporativismo. En lo social, visión armónica de la sociedad, una vez superado el feudalismo en que se localizan las injusticias sociales,

\footnotetext{
75 José Dalmáu Carles, Enciclopedia (1927), 9, 13, 16, 21-22, 43 y 53, y Enciclopedia (1953), 612, 627, 628 y 640 .

${ }^{76}$ Alfonso Capitán Díaz, Historia de la Educación en España II. Pedagogía Contemporánea (Madrid: Dykinson, 1994), 515-531.
} 
que ya parecen superadas. En lo identitario, nacionalismo español, muy alejado de la idea de Europa (se legitima el proteccionismo económico imperante), compatible sólo con el romanticismo catalanista y el orgullo de la Hispanidad, única referencia exterior. En lo religioso, reivindicación del papel histórico de la Iglesia, institución divina; el catolicismo condiciona la cultura (no tiene cabida, por ejemplo, el evolucionismo), el poder (catolicismo como virtud del que lo ejerce), la moral (matrimonio, frugalidad), la sociedad (corporativismo), la identidad nacional, una suerte de nacionalcatolicismo compatible con las instituciones liberales. En lo político, liberalismo conservador de raigambre jovellanista, que no reivindica las raíces intelectuales del liberalismo (Ilustración), ni siquiera algunas de las libertades que le son propias (de conciencia, libertad religiosa), sino la constitución histórica: monarquía, catolicismo. Impone un concepto de ciudadanía a mitad de camino entre el liberalismo y el comunitarismo; y la cultura política del súbdito pues, más allá de la elección, pone en valor las virtudes innatas, el carisma, el militarismo, el patriotismo y la moral católica de los que están llamados a regir los destinos de España. El carlismo queda identificado con el absolutismo; la democracia o la República significan sólo la alteración del orden natural de las cosas y disminución de «valores». En esencia, son los principios que convienen a una derecha oligárquica, que tiene como referentes a Narváez y Cánovas del Castillo, pero que no olvida ni la represión de los liberales en la época de Fernando VII, ni que Sagasta colaboró con el rey Alfonso XII en la tarea de regenerar España. Pero este manual refleja también la desazón por la acumulación de problemas (Marruecos, Semana Trágica) en el reinado de Alfonso XIII. Por eso, además de a la monarquía, se aferra reiteradamente al corporativismo, a la visión orgánica y armónica de la sociedad para difuminar la lucha de clases. Un corporativismo que a estas alturas es transversal: es compartido por la Iglesia (Rerum Novarum), la vieja extrema derecha carlista, la vieja derecha liberal, cada vez más autoritaria (maurismo) o el catalanismo. El corporativismo es una nueva versión de la concordia ordinum formulada por Cicerón en los estertores de la República romana: Cicerón, como todos estos grupos políticos, además del entendimiento de las clases, también tenía claro el papel rector de la clase senatorial.

De la misma manera que la editorial Dalmau Carles Pla permite acercarnos a la naturaleza del régimen de la Restauración y a los miedos que 
acosan a sus clases rectoras, también nos permite una valoración semejante de la Segunda República. La labor educativa de la Segunda República (bienio reformista) es encomiable. ${ }^{77}$ Condicionada por la Institución Libre de Enseñanza, quiso construir una «República de ciudadanos» fieles a un Estado Nacional y no a la Iglesia, ${ }^{78}$ pero no elaboró un nuevo plan de estudios ni nuevos programas. ${ }^{79}$ La edición de Dalmau Carles de 1936 legitima el nuevo régimen la Constitución de 1931 y sus instituciones, pero no inculca la cultura política de la participación, la propia de un régimen democrático, sino la cultura del súbdito y la obediencia al nuevo poder constituido. No cambia tampoco la filosofía de la edición de 1927, por lo que la legitimación del nuevo régimen queda alicorta: la identidad católica de España es contraria al laicismo republicano; el corporativismo o el desconocimiento de las contradicciones sociales son contrarios a la voluntad republicana de reformar ciertas estructuras (reforma agraria y educativa); la identificación de la Primera República con la erosión de valores no contribuye a legitimar la Segunda. Esto desdice la supuesta identidad republicana de Josep Dalmau Carles que sostienen algunos de sus biógrafos; su liberalismo también se subordina a condicionantes prepolíticos: quizás pesó más en él el mercado que los principios. Pero esta pusilanimidad es también indicativa de la escasa solidez en España de los periodos democráticos, siempre frustrados por golpes de estado e incapaces de alterar el entramado institucional oligárquico. ${ }^{80}$ Incapaces también de subvertir su sistema de valores, o de socializar a los alumnos en valores alternativos que legitimen la democracia, la participación, la justicia social.

La edición de 1953 permite acercarnos a la naturaleza del franquismo. Este régimen puede asumir la filosofía de la edición de 1927: la constitución histórica, el corporativismo, la institución divina de la Iglesia son también contenidos ideológicos del franquismo. Pero la edición de 1953 debe añadir retoques para legitimar el nuevo régimen, obviar los conflic-

\footnotetext{
${ }_{77}$ Análisis detallado en Historia de la Educación en España IV. La educación durante la II República y la Guerra Civil, 1931-1939 (Madrid: MEC-Secretaría General Técnica, 1991). Estudio preliminar por Antonio Molero Pintado, 13-130.

${ }^{78}$ Sandie Holguín, República de ciudadanos. Cultura e identidad nacional en la España republicana (Barcelona: Crítica, 2002), 41.

79 Juan Manuel Fernández Soria, Educación, socialización y legitimación política: España, 1931-1970 (Valencia: Tirant lo blanch, 1998), 55-56.

80 Jordi Solé Tura y Eliseo Aja, Constituciones y periodos constituyentes en España, 1808-1836 (Madrid: Siglo XXI, 1983), 118-144.
} 
tos centro-periferia, recalcar el sentido universal de la Hispanidad y la unidad de destino, acomodar la Historia Sagrada a un régimen dictatorial y autárquico. Y legitimar, además del conservadurismo monárquico y oligárquico, la vieja extrema derecha carlista, que ya no es absolutismo, sino el recobro de la esencia tradicional de España, la nueva extrema derecha falangista, cuyos valores modernos (unidad de destino, teorización del Imperio) quedan asumidos en mezcolanza con los propios del nacionalcatolicismo eclesial, y la Dictadura de Primo de Rivera que sirve de referente. Esta legitimación es paralela a la deslegitimación de la Segunda República, o al olvido de los mártires del liberalismo y de la contribución de Sagasta a la estabilización del sistema de la Restauración. También la derecha tradicional de la Restauración, por miedo a la revolución, progresivamente abraza posturas antiliberales y autoritarias. Franco dio a cada una de las fuerzas de la coalición vencedora de la Guerra Civil (monárquicos alfonsinos, carlistas, falangistas, católicos, militares) una parcela de poder: los manuales de Historia no hacen sino justificar a todas ellas para salvaguardar la unidad del régimen. ${ }^{81}$

Las tres ediciones de Dalmau Carles legitiman los valores que convienen a las oligarquías que construyeron en España el Estado liberal a través de un pacto con las fuerzas del Antiguo Régimen: respeto por la constitución histórica, olvido del proyecto de cambio de la Ilustración, historia hegemónica, visión armónica de la sociedad, corporativismo, pensamiento eclesial, nacionalismo. Esa oligarquía, que controla la mayor parte del tiempo político de la historia contemporánea española, es el auténtico eje vertebrador del sistema educativo español. El liberalismo doctrinario, el propio de las oligarquías, es el que convierte la soberanía nacional en soberanía de la inteligencia, la de los llamados a gobernar, y el que convierte el sistema educativo nacional creado por las Cortes de Cádiz, un sistema dirigido por el Parlamento, que prioriza una educación elemental para todos, en un sistema educativo estatal dirigido por el Gobierno, que prioriza la preparación de cuadros para la Administración. ${ }^{82}$ La historiografía escolar es coherente con el mismo. Dalmau Carles no es una excepción. Siempre proclive a unas elites, elegidas o no, defensoras a ultranza del orden, en un marco político liberal (Restauración: edición

${ }^{81}$ Sobre esta cuestión, Emilio Castillejo Cambra, Mito, legitimación y violencia simbólica, 479-499.

82 Manuel de Puelles Benítez, Estado y educación en la España liberal (1809-1857). Un sistema educativo nacional frustrado (Barcelona: Pomares, 2004), 118-119 y 173. 
de 1927) o democrático (Segunda República: edición de 1936), puede acercarse a los tópicos del liberalismo: Riego, Sagasta, comuneros como mártires de las libertades, carlistas identificados con el absolutismo. Y si se trata de una editorial de la periferia, como es el caso, a los tópicos del foralismo: la nostalgia por las libertades perdidas en 1591, 1640, 1714 y 1876. Pero cuando ese orden sacralizado, tras una amenaza traumática como la Segunda República, ha sido restaurado por un régimen salvador como el franquismo, no caben ni sensibilidades liberales, ni foralistas, ni identidades complejas, sino la complicidad con la vieja extrema derecha carlista y la nueva extrema derecha falangista.

Pero la editorial Dalmau Carles no justifica el franquismo a través de la contrarrevolución, como hacen algunos manuales de Edelvives, el Instituto de España o del Movimiento. Ello exigiría, además de identificar el carlismo con el recobro de la tradición para incorporarlo a la coalición vencedora de la Guerra Civil, una enmienda a la historia contemporánea en su totalidad, eliminar la idea de progreso o convertir a España en el brazo armado de Dios. Lo hace a través de lo que unos llaman «nostalgia liberal», otros visión whig de la historia, y otros bonapartismo: es deseable un sistema que conjugue el orden y la libertad y garantice el progreso, como el que surgió de la revolución inglesa de 1688, pero el radicalismo y extremismo - de izquierdas- justificarían una intervención militar para restablecer el orden perdido. ${ }^{83}$ Se impone así el mito del radicalismo. De esta manera, para Dalmau Carles, en el reinado de Isabel II se realizaron "grandes adelantos materiales» y «el nivel de la cultura se elevó a gran altura», Narváez acabó con el «bandolerismo» y modernizó el sistema de enseñanza; el Sexenio revolucionario, en cambio, sólo significa disturbios y erosión de «los valores públicos»: quedan legitimados el golpe de Pavía con el consenso de «los personajes políticos de los diferentes partidos» y el golpe de Martínez Campos que no tuvo resistencias. Y vuelta a empezar. En la Restauración, Cánovas (no ya Sagasta), «contribuyó eficazmente al resurgimiento de España», pero dado que «los gobiernos monárquicos a duras penas podían ir afrontando los problemas, más apremiantes cada día», Primo de Rivera intervino para «encauzar la vida política de España», a la que proporcionó «años de

83 Sobre estos conceptos, Emilio Castillejo Cambra, Mito legitimación y violencia simbólica, 69-72, 291-294 y 483-510. 
paz y gran prosperidad». La Segunda República, ilegítima, proclamada "con el pretexto" de unas elecciones municipales, "peor que la primera», «extremó su orientación partidista». Corresponde entonces legitimar a Falange y el «Alzamiento». ${ }^{84}$

\section{Nota sobre el autor:}

Emilio Castillejo Cambra es Doctor en Historia por la Universidad Pública de Navarra (UPNA). Su labor investigadora se ha centrado en el análisis de los contenidos ideológicos de los manuales escolares tanto del pasado como de la actualidad. Entre otras publicaciones, destacan los libros Mito, Legitimación y violencia simbólica en los manuales de historia del franquismo, 1936-1975 (Madrid: UNED-Serie MANES, 2008) y La enseñanza de la Religión católica en España desde la Transición (Madrid: La Catarata, 2012).

\section{Referencias:}

Almond, Gabriel A., y Sidney Verba. «La cultura política». In Diez textos básicos de Ciencia política, edited by Albert Batlle, 171-190. Barcelona: Ariel, 1992.

Atienza Cerezo, Encarna, y Teun A. VAN Disk. «Identidad social e ideología en libros de texto españoles de Ciencias Sociales». Revista de Educación 353 (2010): 57- 106.

BURKERT, Walter. La creación de lo sagrado. La huella de la biología en las religiones antiguas. Barcelona: Acantilado, 2012.

Capitán Díaz, Alfonso. Historia de la Educación en España II. Pedagogía Contemporánea. Madrid: Dykinson, 1994.

Castillejo Cambra, Emilio. «La función de los mitos sobre «la Guerra de la Independencia» transmitidos a través de la enseñanza de la historia». In Guerra, sociedad y política (1808-1814) I, edited by Francisco Miranda Rubio. Pamplona: Gobierno de Navarra, Departamento de Cultura y Turismo, Institución Príncipe de Viana, Universidad Pública de Navarra, 2008.

- Mito, legitimación y violencia simbólica en los manuales escolares de Historia del franquismo, 1936-1975. Madrid: UNED-Serie MANES, 2008.

CASTILlo, Montserrat. Grans il.lustradors del llibre per a infans catalans, 19051939. Barcelona: Biblioteca de Catalunya, 1997.

${ }^{84}$ José Dalmáu Carles, Enciclopedia (1953), 379, 381 y 383-389. 
Connolly de Pernas, Eduardo. «Josep Dalmau Carles: maestro, republicano y editor». Hibris: revista de bibliofilia 34 (2006): 37-40.

CUART MONER, Baltasar. «La larga marcha hacia las historias de España en el siglo XVI». In La construcción de las Historias de España, edited by Ricardo García Cárcel, 111-123. Madrid: Marcial Pons, 2004.

CuESTA FERNÁNDEZ, Raimundo. Sociogénesis de una disciplina escolar: la Historia. Barcelona: Pomares Corredor, 1997.

Escolano Benito, Agustín. «Libros escolares para programas cíclicos. Epítomes, compendios y tratados. Las primeras enciclopedias». In Historia ilustrada del libro escolar en España. Del Antiguo Régimen a la Segunda República, edited by Agustín Escolano Benito, 425- 44. Madrid: Fundación Germán Sánchez Ruipérez,1997.

- «Tradición e innovaciones en los libros de iniciación a la lectura de la España de entre siglos». In Historia ilustrada del libro escolar en España. Del Antiguo Régimen a la Segunda República, edited by Agustín Escolano Benito, 229254. Madrid: Fundación Germán Sánchez Ruipérez, 1997.

FERNÁNDEz SoRIA, Juan Manuel. Educación, socialización y legitimación política: España, 1931-1970. Valencia: Tirant lo Blanch, 1998.

Foucault, Michel. Microfísica del poder. Madrid: Ediciones La Piqueta, 1992.

Gómez R. DE CASTRo, Federico. «Lecciones de cosas y centros de interés». In Historia ilustrada del libro escolar en España. Del Antiguo Régimen a la Segunda República, edited by Agustín Escolano Benito, 449- 466. Madrid: Fundación Germán Sánchez Ruipérez,1997.

GonZÁlez, Agàpito, Josep et al., Tradició i renovació pedagògica, 1898- 1939. Barcelona: Institut d'Estudis Catalans, Publicacions de l'Abadìa de Montserrat, 2002.

GonzÁlez, Agàpito, Josep, y Salomó MarquÉs i SuREdA. «El libro escolar en catalán». In Historia ilustrada del libro escolar en España. II. Del Antiguo Régimen a la Segunda República, edited by Agustín Escolano Benito, 561- 571. Madrid: Fundación Germán Sánchez Ruipérez, 1997.

González Cuevas, Pedro Carlos. Historia de las derechas españolas. De la Ilustración a nuestros días. Madrid: Biblioteca Nueva, 2000.

Hernández Díaz, José M. « «A Dios gracias, África empieza en los Pirineos». La negación de Europa en los manuales escolares de la España de posguerra, 1939- 1945». Historia de la Educación 20 (2001): 369-392.

Holguín, Sandie. República de ciudadanos. Cultura e identidad nacional en la España republicana. Barcelona: Crítica, 2002.

LÓPEZ FACAL, Ramón. «Enseñar la historia de la gente». In Historia y proyecto social, edited by Josep Fontana. Barcelona: Crítica-Universitat Pompeu Fabra, 2004. 
LÓPEZ FACAL, Ramón. "El nacionalismo español en los manuales de Historia». Educació i Història. Revista d'Història de l'educació 2 (1995).

MARquÉs, Salomó. "L'esplendor del magisteri gironí». In La renovació de l'escola pública del Empordà a tot Catalunya (1900-1939), edited by Salomó Marquès. Figueres-Girona: Generalitat de Catalunya, Societat d'Història de l'Educació dels Paisos de LLengua Catalana, 2013.

Molero Pintado, Antonio. Historia de la Educación en España IV. La educación durante la II República y la Guerra Civil, 1931-1939. Madrid: MEC-Secretaría General Técnica, 1991.

NAvarro, Maria Pilar. "Escola Nova: una nova pedagogía de la lectura a Catalunya». Educació i Historia: Revista d'Història de l'Educació 22 (2013): 65-92.

OssenBACH, Gabriela, y Miguel Somoza. Los manuales escolares como fuente para la historia de la educación en América Latina. Madrid: UNED, 2009.

PEÑA, Javier. «La ciudadanía». In Teoría política: poder, moral, democracia, edited by Aurelio Arteta, Elena García Guitián and Ramón Máiz. Madrid: Alianza, 2003.

PÉrez-Agote, Alfonso. "Nación y nacionalismo: la politización de la identidad colectiva». In Sociedad y politica. Temas de sociología política, edited by Jorge Benedicto and María Luz Morán. Madrid: Alianza, 1995.

PetTit, Philip. Republicanismo. Una teoría sobre la libertad y el gobierno. Barcelona: Paidós, 1999.

Puelles Benítez, Manuel de. Estado y educación en la España liberal (18091857). Un sistema educativo nacional frustrado. Barcelona: Pomares, 2004.

- «La política del libro escolar en España, 1813-1939». In Historia ilustrada del libro escolar en España. Del Antiguo Régimen a la Segunda República, edited by Agustín Escolano Benito. Madrid: Fundación Germán Sánchez Ruipérez,1997.

- «Religión y escuela pública en nuestra historia: antecedentes y procesos». Bordón 58 (2006): 524 y 526.

Puig, Lluis M. de. «Francesc Cambó: paradoxes i contradiccions. Una història en revisió». Annals de l'Institut D'Estudis Gironins vol. 39 (1998), 378-394.

SANI, Giacomo. "Cultura política». In Diccionario de politica, $a-j$, edited by Norberto Bobbio, Nicola Matteucci and Gianfranco Pasquino. Madrid: Siglo XXI editores, 1991.

SANTIAGO, José. «Las formas de sacralización del nacionalismo: un desafío a la secularización». In Sagrado/ Profano. Nuevos desafíos al proyecto de la modernidad, edited by Josetxo Beriain and Ignacio Sánchez de la Yncera, 349- 365. Madrid: CIS, 2010.

SolÉ TuRA, Jordi, y Eliseo Aja. Constituciones y periodos constituyentes en España, 1808-1836. Madrid: Siglo XXI, 1983.

WeBER, Max. Sociología de la religión. Madrid: Istmo, 1997. 